\title{
Neck circumference as a potential marker of metabolic syndrome among college students ${ }^{1}$
}

\author{
Dayse Christina Rodrigues Pereira ${ }^{2}$ \\ Márcio Flávio Moura de Araújo ${ }^{3}$ \\ Roberto Wagner Júnior Freire de Freitas ${ }^{4}$ \\ Carla Regina de Souza Teixeira ${ }^{5}$ \\ Maria Lúcia Zanetti ${ }^{5}$ \\ Marta Maria Coelho Damasceno ${ }^{6}$
}

Objective: to relate neck circumference with metabolic syndrome and its criteria among college students. Method: cross-sectional study conducted with 702 college students in Fortaleza, CE, Brazil from September 2010 to June 2011. Socio-demographic data, waist circumference and neck circumference were collected together with blood pressure, fasting blood sugar, triglyceride levels, and HDL-C. Results: $1.7 \%$ of the studied sample presented metabolic syndrome. Of these, $58.3 \%$ presented altered neck circumference $(p<0.006)$. As neck circumference decreases, pressure levels improve $(p<0.001)$. Additionally, college students with high fasting blood sugar $(p=0.003)$ and high triglyceride levels $(p<0.001)$ presented higher values of neck circumference. Conclusion: neck circumference is a potential predictive marker in the detection of metabolic syndrome and its components among college students.

Descriptors: Anthropometry; Neck Circumference; Nursing; Diabetes Mellitus.

\footnotetext{
1 Supported by Conselho Nacional de Desenvolvimento Científico e Tecnológico (CNPq), Brazil, process \# 474902/2009-9.

2 MSc, Professor, Faculdade de Juazeiro do Norte, Juazeiro do Norte, CE, Brazil.

3 PhD, Adjunct Professor, Instituto de Ciências da Saúde, Universidade da Integração Internacional da Lusofonia Afro Brasileira, Redenção, CE, Brasil.

${ }^{4} \mathrm{PhD}$, Adjunct Professor, Departamento de Enfermagem, Universidade Federal do Piauí, Floriano, PI, Brazil.

${ }_{5}$ PhD, Associate Professor, Escola de Enfermagem de Ribeirão Preto, Universidade de São Paulo, WHO Collaborating Centre for Nursing Research Development, Ribeirão Preto, SP, Brazil.

${ }^{6} \mathrm{PhD}$, Adjunct Professor, Faculdade de Farmácia Odontologia e Enfermagem, Universidade Federal do Ceará, Fortaleza, CE, Brazil.
}

\author{
Corresponding Author: \\ Maria Lúcia Zanetti \\ Universidade de São Paulo. Escola de Enfermagem de Ribeirão Preto \\ Departamento de Enfermagem Geral e Especializada \\ Av. Bandeirantes, 3900 \\ Bairro: Monte Alegre \\ CEP: 14040-902, Ribeirão Preto, SP, Brasil \\ E-mail: zanetti@eerp.usp.br
}

Copyright @ 2014 Revista Latino-Americana de Enfermagem This is an Open Access article distributed under the terms of the Creative Commons Attribution Non-Commercial License (CC BY-NC).

This license lets others distribute, remix, tweak, and build upon your work non-commercially, and although their new works must also acknowledge you and be non-commercial, they don't have to license their derivative works on the same terms. 


\section{Introduction}

The National Priorities for Research and the Research Agenda in the health field gives priority in one of its sub-agendas to non-communicable diseases (NCDs), such as hypertension, diabetes mellitus and obesity $^{(1)}$. Metabolic syndrome (MS) is also added to this context, the diagnosis of which may include these diseases; the disease also increases the risk for developing cerebrovascular and coronary artery diseases $^{(2)}$. Metabolic syndrome is defined as a separate entity based on risk factors for cardiovascular diseases and type-2 diabetes mellitus (DM2). Factors related to MS include visceral obesity, dyslipidemia, arterial hypertension, and insulin resistance. MS should be recognized before the clinical manifestation of DM2 in order to implement primary prevention through lifestyle modifications and should specifically treat each of the syndrome components ${ }^{(3-4)}$.

There are various sources providing criteria for identifying $\mathrm{MS}^{(3-4)}$, however, those established by the National Cholesterol Education Program - Adult Treatment Panel III (NCEP ATP III) and recommended by the I Brazilian Guideline for the Diagnosis and Treatment of Metabolic Syndrome, are more frequently used in clinical studies due to their practicality. These programs consider the presence of three or more criteria to indicate the presence of metabolic syndrome, namely: waist circumference greater than $88 \mathrm{~cm}$ in women and $102 \mathrm{~cm}$ in men, triglycerides above 150mg/ dl, HDL cholesterol below $40 \mathrm{mg} / \mathrm{dl}$ in men or $50 \mathrm{mg} /$ dl in women, blood pressure above or equal to $130 / 85$ $\mathrm{mmHg}$, and circulating glucose greater than or equal to $110 \mathrm{mg} / \mathrm{dl}^{(3)}$.

The search for easily applicable clinical criteria to identify MS led researchers to consider the importance of investigating other anthropometric parameters to integrate or replace some of those already established $^{(5)}$. Therefore, neck circumference (NC) began to be investigated under the argument that there are limitations in regard to waist circumference measurement (i.e. lack of a standard measurement technique, variations in certain health conditions) and also because neck measurements, under normal conditions, do not oscillate throughout the day ${ }^{(6-8)}$.

Hence, neck circumference is now considered a risk marker for MS, even though further investigation with different populations is still recommended(8-11).

In Brazil, neck circumference was investigated as part of the Brazilian Metabolic Syndrome Study (BRAMS) that included adult outpatients (between 18 and 60 years old) undergoing treatment for DM2, metabolic syndrome and/or obesity. The results found so far show that neck circumference is an innovative and additional parameter to determine the distribution of body fat, which is associated with visceral fat, to metabolic syndrome's components and insulin resistance, especially among women(12).

The city of Fortaleza, CE, Brazil was included in BRAMS, but neck circumference as an MS marker has not yet been studied in predominantly young populations. Hence, considering anthropometry as a tool to be used in Nursing consultations and also that the National Priorities for Research and the Research Agenda in the health field point to the need to develop and use healthpromoting methods in addition to preventive, diagnostic, and early treatment methods ${ }^{(1)}$, this study's objective was to relate neck circumference to metabolic syndrome and its criteria among college students.

This study is justified by the scarcity of studies addressing this topic in Brazil and because it can support improved healthcare delivery, regardless of the context in which these actions are developed.

\section{Method}

This cross-sectional study was performed at the Federal University of Ceará (UFC) in the campuses of Fortaleza, CE, Brazil. The sample was calculated using a formula for infinite populations. A prevalence of $50 \%$ was adopted because it provides the maximum sample size, with a level of significance of $a=0.05$ and an absolute sampling error of $4 \%$. To minimize potential losses, $10 \%$ was added to the sample size ( $n=702$ college students). The participants were distributed in the following fields: human sciences, exact sciences, agricultural sciences, health sciences, sciences and technology. Based on the population per field of knowledge, the sample was stratified in such a way that 143,116, 98, 106, 127 and 112 students were studied, respectively.

Students from the following programs participated in the study: Pedagogy, Social Sciences and Letters in the area of the human sciences; Business, Economy and Accounting Programs from the exact sciences; Animal Science, Agronomy, and Fishing Engineering from the agricultural sciences; from the Nursing and Pharmacy programs from the health sciences; and Chemistry, Geography from the sciences; biological sciences and technology; and Electrical, Metallurgical, and Civil Engineering. 
Inclusion criteria were: being properly enrolled in brick-and-mortar undergraduate programs in daytime hours; living in Fortaleza, CE, Brazil; and having a phone number and email. Pregnancy was an exclusion criterion.

Socio demographic variables included: sex (male and female); age (16-58 years old); race (Caucasian, biracial, Afro-descendant, Asian); marital status (married/stable union, single, widowed, separated/ divorced); occupational situation (whether only study or also work); grade (current semester); beginner (is attending first half of the program); senior (is attending second half of the program); economic situation ( $A 1$, A2, B1, B2, C, D, E according to the Criteria of Brazil Economic Classification established by the Brazilian Association of Business and Research)(13), and with whom the individual lives with (parents, relatives, friends, spouse/partner, alone).

The following were established for anthropometric, clinical and biochemical variables: central obesity (waist circumference [WC] greater than $102 \mathrm{~cm}$ for men and $88 \mathrm{~cm}$ for women); neck circumference [NC] greater than or equal to $39 \mathrm{~cm}$ for men and greater than or equal to $35 \mathrm{~cm}$ for women)(12); high blood pressure (greater or equal to $130 / 85 \mathrm{mmHg}$ ); high triglycerides level (greater or equal to $150 \mathrm{mg} / \mathrm{dl}$ ); low HDL cholesterol level (below $40 \mathrm{mg} / \mathrm{dl}$ for men and below $50 \mathrm{mg} / \mathrm{dl}$ for women); and circulating glucose greater than or equal to $110 \mathrm{mg} / \mathrm{dl})^{(3)}$.

The researcher assistants (two doctoral and two master's students along with two undergraduate students) responsible for collecting data received 30 hours of training to ensure the reliability of data. Data collection was performed from September to November 2010 and from February to June 2011 in private rooms on the university's premise.

The students were recruited in classrooms after the study's objectives and methodology was clarified. Those who consented signed free and informed consent forms and completed a questionnaire addressing sociodemographic data. The day and time for measuring neck circumference (NC), waist circumference (WC) and blood pressure (BP), and collecting blood samples, was also scheduled. The researchers contacted the students on the day before the scheduled time to remind them of the need to fast for 12 hours.

The participants stood erect with their heads positioned in the Frankfurt horizontal plane at the time of measuring NC. An inelastic metric tape was placed at the midpoint of the neck's height. The measure was taken immediately below Adam's apple ${ }^{(14-16)}$ among the male participants. Waist circumference (WC) was measured with an inelastic tape placed on the skin at the midpoint between the iliac crest and the last rib at the end of the expiratory breathing(16-17). Blood pressure was measured in accordance with Brazilian guidelines ${ }^{(18)}$. The collection of a venous blood sample was performed by technicians from a specialized laboratory in accordance with standards guiding the preservation of samples and the safety of individuals. A free snack was provided after blood sample collection. The project was approved by the Institutional Review Board guiding research with human subjects at the Federal University of Ceará (Protocol No. 208/10).

Data were triple-entered into Excel and then imported into IBM-SPSS, version 14.0. Statistical measures, average, standard deviation, and odds ratios were computed with their respective confidence intervals of $95 \%\left(\mathrm{CI}_{95 \%}\right)$. Before comparing averages, we verified the normality of data and equality of variances using the Kolmogorov-Smirnov and Levene tests, respectively. NC averages were analyzed using Student's t-test for independent data and Snedecor's F-test. In the latter, when $\mathrm{p}<0.05$, multiple comparisons were performed using the Tukey test (if variations were equal) or the Games-Howell test (if variances were not equal). Associations among NC and risk groups were analyzed using the Chi-square $\left(\chi^{2}\right)$.

\section{Results}

Of the 702 college students, $62.7 \%$ were women; $53.3 \%$ were aged between 20 and 24 years old (21.5 \pm 1.57$) ; 49.3 \%$ were biracial; $92.3 \%$ were single; $69.1 \%$ were in their first to the fifth semester; $71.2 \%$ lived with their parents; and $65.2 \%$ studied only. There was a predominance of socioeconomic classes $B$ and $C$ (39.5\%), with monthly family income of U\$ 1,705 dollars $(S D=200)$. This variable presented an asymmetric distribution at right (Kolmogorov Sminorv com $p<0.001$ ).

When comparing the averages of association between NC and the socio-demographic data, statistically significant association was found in regard to sex $(p<0.001)$, age $(p=0.009)$, and occupational situation $(p<0.001)$. Therefore, male students aged $\geq$ 25 years old and those who worked besides studying presented the highest measure of neck circumference.

The NC of men and women who presented high WC was greater than that of individuals with normal NC $(p<0.001)$. Additionally, as NC decreases, the BP of the participants improves $(p<0.001)$. Individuals with high FBS $(p=0.003)$ and TG $(p<0.001)$ presented higher NC, as opposed to what happened with HDL-C (Table 1). 
The percentages of students with changes simultaneously between NC and the biochemical criteria of MS, that is, FBS $(p<0.005)$, TG $(p<0.001)$ and HDL-C $(p<0.004)$, were $33.3 \%, 32.1 \%$ and $9.8 \%$, respectively. These values were lower among those with normal biochemical measures and NC (Table 1).

Table 1 - Association between Neck Circumference and the components of Metabolic Syndrome. Fortaleza, CE, Brazil, 2011

\begin{tabular}{|c|c|c|c|c|c|c|}
\hline \multirow{2}{*}{ Variables } & \multicolumn{2}{|c|}{ High } & \multicolumn{2}{|c|}{ Under normal limits } & \multirow{2}{*}{$\mathrm{RC}: \mathrm{Cl}_{95 \%}$} & \multirow{2}{*}{$P$ value } \\
\hline & $\mathbf{n}$ & $\%$ & $\mathbf{n}$ & $\%$ & & \\
\hline \multicolumn{7}{|c|}{ Waist circumference (WC) under normal limits } \\
\hline Male & 128 & 18.8 & 554 & 81.2 & $1.7 ; 1.2-2.5$ & $<0.001$ \\
\hline Female & 68 & 11.4 & 528 & 88.6 & 1 & \\
\hline \multicolumn{7}{|l|}{ High waist circumference (WC) } \\
\hline Male & 18 & 100 & - & - & $1.3 ; 1.1-1.4$ & $<0.017$ \\
\hline Female & 78 & 75.0 & 26 & 25.0 & 1 & \\
\hline \multicolumn{7}{|l|}{ Blood pressure } \\
\hline Hypertension & 12 & 55.0 & 9 & 45.0 & $7.5 ; 2.8-20.8$ & $<0.001$ \\
\hline Borderline & 14 & 45.2 & 17 & 54.8 & $4.6 ; 2.0-10.4$ & $<0.001$ \\
\hline Normal & 36 & 40.4 & 53 & 59.6 & $3.8 ; 2.2-6.3$ & $<0.001$ \\
\hline Excellent & 84 & 15.0 & 475 & 85.0 & 1 & \\
\hline \multicolumn{7}{|l|}{ Fasting blood sugar (FBS) } \\
\hline Under normal parameters & 28 & 33.3 & 56 & 66.7 & $2.0 ; 1.2-3.5$ & $<0.005$ \\
\hline Above normal parameters & 117 & 19.3 & 489 & 80.7 & 1 & \\
\hline \multicolumn{7}{|l|}{ Triglycerides (TG) } \\
\hline Under normal parameters & 51 & 32.1 & 108 & 67.9 & $2.1 ; 1.4-3.3$ & $<0.001$ \\
\hline Above normal parameters & 94 & 17.7 & 436 & 82.3 & 1 & \\
\hline \multicolumn{7}{|l|}{ High density lipoprotein (HDL-C) } \\
\hline Under normal parameters & 8 & 9.8 & 75 & 90.2 & $0.3 ; 0.1-0.7$ & $<0.004$ \\
\hline Above normal parameters & 137 & 22.6 & 469 & 77.4 & 1 & \\
\hline
\end{tabular}

Table 2 - Comparison of averages concerning association between Neck Circumference and the components of Metabolic Syndrome. Fortaleza, CE, Brazil, 2011

\begin{tabular}{|c|c|c|c|}
\hline Variables & Average & \pm Standard error of the mean & $P$ value \\
\hline \multicolumn{4}{|l|}{ Waist circumference (WC) } \\
\hline Male & & & $<0.001$ \\
\hline Under normal parameters & 33.61 & 0.123 & \\
\hline Above normal parameters & 41.06 & 0.631 & \\
\hline Female & & & $<0.001$ \\
\hline Under normal parameters & 33.00 & 0.115 & \\
\hline Above normal parameters & 38.37 & 0.279 & \\
\hline Blood pressure & & & $<0.001$ \\
\hline Excellent & 33.12 & 0.130 & \\
\hline Normal & 36.00 & 0.358 & \\
\hline Borderline & 37.53 & 0.448 & \\
\hline Hypertension & 37.13 & 0.854 & \\
\hline Fasting blood sugar (FBS) & & & 0.003 \\
\hline Under normal parameters & 33.67 & 0.136 & \\
\hline Above normal parameters & 34.84 & 0.396 & \\
\hline Triglycerides & & & $<0.001$ \\
\hline Under normal parameters & 33.53 & 0.139 & \\
\hline Above normal parameters & 34.79 & 0.306 & \\
\hline High density lipoprotein (HDL-C) & & & $<0.001$ \\
\hline Under normal parameters & 33.99 & 0.141 & \\
\hline Above normal parameters & 32.57 & 0.285 & \\
\hline
\end{tabular}

Only $1.7 \%$ of the sample present MS, $58.3 \%$ of which simultaneously presented MS and altered NC $(p<0.006)$. Additionally, individuals with MS presented higher NC in regard to the other participants $(p<0.001)$ (Table 3). 
Table 3 - Association between Neck Circumference and Metabolic Syndrome among college students. Fortaleza, CE, Brazil, 2011

\begin{tabular}{|c|c|c|c|c|c|c|c|c|c|}
\hline \multirow[t]{2}{*}{ Variables } & \multicolumn{2}{|c|}{$\begin{array}{c}\text { Above normal } \\
\text { parameters }\end{array}$} & \multicolumn{2}{|c|}{$\begin{array}{c}\text { Under normal } \\
\text { parameters }\end{array}$} & \multirow{2}{*}{$\mathbf{R C}: \mathbf{C l}_{95 \%}$} & \multirow[t]{2}{*}{$P$ value } & \multirow[t]{2}{*}{ Mean } & \multirow{2}{*}{$\begin{array}{l}\text { Standard error } \\
\text { of the mean }\end{array}$} & \multirow[t]{2}{*}{$P$ value } \\
\hline & $\mathbf{n}$ & $\%$ & $\mathbf{n}$ & $\%$ & & & & & \\
\hline Metabolic Syndrome & & & & & & $<0.006$ & & & $<0.001$ \\
\hline Yes & 7 & 58.3 & 5 & 41.7 & $5.4 ; 1.4-22.1$ & & 37.04 & 1.199 & \\
\hline No & 138 & 20.4 & 539 & 79.6 & 1 & & 33.76 & 0.129 & \\
\hline
\end{tabular}

\section{Discussion}

The relationship between NC and sex showed that men presented higher neck circumference values. Other studies, however, found this association in both sexes and this issue has not been totally clarified ${ }^{(9,12,14)}$. It is possible that the predominance of excess weight among women explains the greater female vulnerability to higher $\mathrm{NC}^{(19)}$.

Despite the prevalence of MS being low among college students, a significant association was found with high NC. Additionally, those with one or two MS components, also presented a higher average NC; however, more robust evidence was detected in regard to NC and WC, NC and BP, and NC and TG. In this sense, this study's results are in agreement with those found in recent literature(20-23).

Hence, the measurement of NC may help to diagnose MS and various health problems, such as central obesity, pre-hypertension, hypertension and dyslipidemia, in addition to indicating the condition of being overweight and obese ${ }^{(24)}$. One study addressing the relationship between NC and relative muscle force and cardiovascular risk factors among sedentary women showed that NC predicts cardiovascular risk(25). On the other hand, another study with nursing professionals indicates that NC is not sensitive enough to capture metabolic deviations related to blood lipoprotein, as in other measures of body composition ${ }^{(26)}$.

The measurement of NC is a simple, reliable and low cost procedure that enables it to be implemented in primary care by any health worker, whether to prevent diseases or to identify them, reaching large and different populations.

Because this is a cross-sectional study, however, we cannot draw causal relationships, not even for the MS components with statistically significant associations. The criteria used to identify MS may underestimate the number of cases, as they consider the difference of values among criteria established by organizations in regard to central obesity(27).
A lack of Brazilian studies addressing this topic, regardless of the segment of population, as well as of international investigations involving college students, hindered a deeper discussion and comparisons with literature, though it may contribute to BRAMS.

At the same time, this study points to the need to develop further studies including various and different populations in terms of ethnicity, age, health conditions, and other criteria for the diagnosis of MS, to enable comparisons and better clarify NC as an MS marker. Additionally, this study guides those interested in the topic to review current, established criteria to classify MS and avoid underestimation of cases, as well as to consider the possibility of including neck circumference as a marker for metabolic syndrome.

\section{Conclusions}

Neck circumference was associated with MS and all its criteria according to NCEP/ATP III. Therefore, NC is a potential marker as an additional parameter to screen for MS among college students.

\section{References}

1. Agenda Nacional de Prioridade de Pesquisa em Saúde. Brasil; 2008.

2. Alberti KG, Zimmet P, Shaw J. Metabolic syndrome-a new world-wide definition. A Consensus Statement from the International Diabetes Federation. Diab Med. 2006;23(5):469-80.

3. Expert Panel on Detection, Evaluation, and Treatment of High Blood Cholesterol in Adults. Executive Summary of the Third Report of The National Cholesterol Education Program (NCEP) Expert Panel on Detection, Evaluation, And Treatment of High Blood Cholesterol In Adults (Adult Treatment Panel III). JAMA. 2001;285(19):2486-97.

4. International Diabetes Federation (IDF). International Diabetes Federation consensus worldwide definition of the metabolic syndrome [Internet]. 2008; [acesso 31 
mar 2014]; Disponível em: http://www.idf.org/webdata/ docs/IDF_Metasyndrome_definition.pdf.

5. Schommer VA, Barbiero SM, Cesa CC, Oliveira R, Silva AD, Pellanda LC. Excess Weight, Anthropometric Variables and Blood Pressure in Schoolchildren aged 10 to 18 years. Arq. Bras. Cardiol. 2014;102(4):312-8.

6. Wang Y, Rimm EB, Stampfer MJ, Willett WC, Hu FB. Comparison of abdominal adiposity and overall obesity in predicting risk of type 2 diabetes among men. Am J Clin Nutr. 2005;81:555-63.

7. Wang J, Thornton JC, Bari S, Williamson B, Gallagher

D, Heymsfield SB, et al. Comparisons of waist circumferences measured at 4 sites. Am J Clin Nutr. 2003;77(2):379-84.

8. Sjöström CD, Lissner $L$, Sjöström L. Relationships between changes in body composition and changes in cardiovascular risk factors: the SOS Intervention Study. Swedish Obese Subjects. Obesity Res. 1997;5(6):519-30.

9. Guang-ran Y, Shen-yuan Y, Han-jing F, Gang W, Liangxiang Z, Xiang-lei B, et al. Neck Circumference Positively Related With Central Obesity, Overweight, and Metabolic Syndrome in Chinese Subjects With Type 2 Diabetes: Beijing Community Diabetes Study 4. Diabetes Care. 2010;33(11):2465-7.

10. Ben-Noun L, Sohar E, Laor A. Neck Circumference as a Simple Screening Measure for Identifying Overweight and Obese Patients. Obesity Res. 2001;9(8):470-7.

11. Ben-Noun L, Laor A. Relationship between changes in neck circumference and cardiovascular risk factors. Exp Clin Cardiol. 2006;11(1):14-20.

12. Stabe C, Vasques AC, Lima MM, Tambascia MA, Pareja JC, Yamanaka A, et al. Neck circumference as a simple tool for identifying the metabolic syndrome and insulin resistance: results from the Brazilian Metabolic Syndrome Study. Clin Endocrinol. 2013;78(6):874-81.

13. Associação Nacional de Empresas de Pesquisas (ANEP). Critério de Classificação Econômica no Brasil. [Internet] 2009. [acesso 14 fev 2009]. Disponível em: www.anep.org.br.

14. Preis SR, Massaro JM, Hoffmann U, D'Agostino RB Sr, Levy D, Robins SJ, et al. Neck circumference as a novel measure of cardiometabolic risk: the Framingham Heart study. J Clin Endocrinol Metab. 2010;95(8):3701-10.

15. Vasques AC, Rosado L, Rosado G, Ribeiro RC, Franceschini S, Geloneze B. Anthropometric indicators of insulin resistance. Arq. Bras. Cardiol. 2010;95(1):e14-e23.
16. World Health Organization (WHO). Obesity: preventing and managing the global epidemic. Report of a WHO Consulation. Geneva: WHO Technical report series 834. World Health Organization; 2000.

17. Gomes MB, Ferreira SDG. Síndrome metabólica, diabetes e risco cardiovascular: aspectos clínicos e terapêuticos. Posicionamento Oficial Sociedade Brasileira de Diabetes; 2009. n. 2/09.

18. Sociedade Brasileira de Cardiologia. VI Diretrizes Brasileiras de Hipertensão. Arq Bras Cardiol. 2010;34:1926-31.

19. Fox CS, Massaro JM, Hoffmann U, Pou KM, Maurovich-Horvat $\mathrm{P}$, Liu CY, et al. Abdominal visceral and subcutaneous adipose tissue compartments: association with metabolic risk factors in the Framingham Heart Study. Circulation. 2007;116(1):39-48.

20. Hingorjo MR, Qureshi MA, Mehdi A. Neck circumference as a useful marker of obesity: a comparison with body mass index and waist circumference. J Pak Med Assoc. 2012;62:36-40.

21. Fitch KV, Stanley TL, Looby SE, Rope AM, Grinspoon SK. Relationship between neck circumference and cardiometabolic parameters in HIV-infected and nonHIV-infected adults. Diabetes Care. 2011;34:102631.

22. Kurtoglu S, Hatipoglu N, Mazicioglu MM, Kondolot $M$. Neck circumference as a novel parameter to determine metabolic risk factors in obese children. Eur J Clin Invest. 2011;42:623-30.

23. Guo X, Li Y, Sun G, Yang Y, Zheng L, Zhang $X$, et al. Prehypertension in children and adolescents: association with body weight and neck circumference. Intern Med. 2012;51:23-7.

24. Ben-Noun L, Sohar E, Laor A. Neck Circumference as a Simple Screening Measure for Identifying Overweight and Obese Patients. Obesity Res. 2001;9:470-7.

25. Tibana RA, Teixeira TG, Farias DL, Silva AO, Madrid $B$, Vieira $A$, et al. Relação da circunferência do pescoço com a força muscular relativa e aos fatores de risco cardiovascular em mulheres sedentárias. Einstein. 2012;10(3):329-34.

26. Alexandria FG, Paraguassu ALS, Maciel AP, Araújo MS, Machado LMM, Filho JAP. Correlações entre circunferência do pescoço, o índice de massa corporal e o perfil lipídico de mulheres, profissionais de enfermagem, de um hospital universitário em Belém, Pará, Brasil. Brasília Méd. 2013;50(1):130-42. 
27. Halpern A. Bases fisiológicas e critérios diagnósticos

da síndrome metabólica. In: Síndrome metabólica:

aspectos etiopatogênicos, clínicos e terapêuticos.

Posicionamento Oficial Sociedade Brasileira de Diabetes;

2009. n. 2/09. 